\title{
Human papillomavirus E7 oncoprotein expression by keratinocytes alters the cytotoxic mechanisms used by CD8 T cells
}

\author{
Purnima Bhat ${ }^{1,2}$, Anne-Sophie Bergot ${ }^{1}$, Nigel Waterhouse ${ }^{3}$ and Ian Hector Frazer ${ }^{1}$ \\ ${ }^{1}$ University of Queensland Diamantina Institute, University of Queensland, Translational Research Institute, Brisbane, Qld, Australia \\ ${ }^{2}$ Medical School, Australian National University, Canberra, Act, Australia \\ ${ }^{3}$ QIMR Berghofer Medical Research Institute, Brisbane, QId, Australia \\ Correspondence to: Ian Hector Frazer, email: i.frazer@uq.edu.au, s.templeman@uq.edu.au \\ Keywords: cervical cancer; head and neck cancer; immunotherapy; cell-mediated killing; time-lapse microscopy \\ Abbreviations: HPV, human papillomavirus; KC, keratinocyte; OVA, ovalbumin; EGFP, enhanced green fluorescent protein \\ Received: November 30, $2016 \quad$ Accepted: April 17, $2017 \quad$ Published: December 14, 2017 \\ Copyright: Bhat et al. This is an open-access article distributed under the terms of the Creative Commons Attribution License 3.0 \\ (CC BY 3.0), which permits unrestricted use, distribution, and reproduction in any medium, provided the original author and source \\ are credited.
}

\section{ABSTRACT}

Cervical cancer is a malignant transformation of keratinocytes initiated by the E7 oncoprotein of human papillomavirus (HPV). These tumors are characterized by keratinocyte hyperproliferation and are often infiltrated with activated CD8 T cells. HPV infection confers changes to gain immunological advantage to promote chronic infection, and these persist with malignant transformation. We investigated the relative importance of the many redundant mechanisms of cytotoxicity used by CD8 T cells to kill keratinocytes expressing HPV E7 oncoprotein using extendedduration time-lapse microscopy that allows examination of cell-to-cell interactions during killing. E7 expression by keratinocytes increased susceptibility to cell-mediated killing. However, while killing of non-transgenic keratinocytes was traditional, perforin-mediated, and caspase-dependent, E7-expression favored killing by perforinindependent, caspase-independent mechanisms. The roles of perforin, TNFa, IFNY, Fas/FasL and PD1/PD-L1 were graded according to target cell survival to produce a hierarchy of killing mechanisms utilized in killing E7-expressing cells. TNFa was essential for perforin-mediated killing of E7-expressing cells, but not perforinindependent killing. IFNy facilitated killing by Fas/FasL interaction, especially in the absence of perforin. Additionally, expression of E7 offered protection from killing by up regulation of PD-L1, Fas and FasL expression on keratinocytes promoting fight-back by target cells, resulting in effector cell death. This study shows that keratinocytes expressing E7 are highly susceptible to killing by CD8 T cells, but utilizing different armamentarium. Down-regulation of CD8 T cell cytotoxicity in HPV-related tumors may be due to suppression by E7-expressing keratinocytes. Immunotherapy for HPVrelated cancers may be improved by suppression of PD-L1, or by suppression of FasL.

\section{INTRODUCTION}

Persisting human papillomavirus infection is the main cause of cervical and anal cancers, and has been implicated in a large number of other epithelial tumors including skin, esophageal, and head and neck cancers [1]. Papillomavirus infects basal replicating keratinocytes $(\mathrm{KC})$ and is cleared by the immune system in the majority of cases resulting in no further clinical progression. In persistent infection, HPV evades clearance by the immune system, increasing the risk for oncogenesis [2]. HPV proteins E6 and E7 are expressed in all cervical cancers, and are responsible for the oncogenic progression of lesions by their suppressive action on the retinoblastoma gene product, resulting in $\mathrm{KC}$ proliferation and suppression of differentiation. HPV infection results 
in maintaining cell cycling, preventing apoptosis, and preventing differentiation, due to expression of its two major oncoproteins, E6 and E7 [3].

Although the immune system has failed to detect and destroy these cells producing non-self, virus-derived, oncogenic proteins, these lesions are often associated with a marked immune cell infiltrate. The presence of CD8 T cells in cervical lesions is associated with a favorable prognosis, with their numbers inversely correlating with tumor progression $[4,5]$. Despite infiltrating tumors, however, effector $\mathrm{T}$ cells are unable to kill their targets [6]. E7-expressing murine skin grafts placed on E7-naïve animals, are not rejected [7]. As skin graft rejection is CD8 T cell dependent, tolerance of E7expressing skin suggests that the E7 oncoprotein plays a role in inhibiting cell-mediated immune function in cervical cancers.

Persistence and transformation of the basal KC by proteins such as E7 is associated with immune evasion. Multiple mechanisms of immune evasion within transformed $\mathrm{KC}$ have been described including Fas downregulation $[8,9]$, downstream effects on apoptosis of downregulation of the retinoblastoma gene [10], alteration of the processing of IFN $\gamma$-dependent intracellular proteins [11, 12, 13], and changes to the TNF receptor and processing [14]. Additionally, the effects of HPV on infiltrating lymphocytes, preventing activation [15], affecting mechanisms of cytotoxicity, or promoting anergy or exhaustion $[15,16]$ may be due to the expression of E7 oncoprotein.

CD8 $T$ cells have a substantial armamentarium with which to kill target cells. Contact-dependent mechanisms including perforin/granzyme and Fas-FasL, and contactindependent mechanisms such as production of TNF $\alpha$ or IFN $\gamma$ - are utilized by CD8 T cells in tumor environments with varying degrees of preference.

We examined the mechanisms by which activated antigen-specific CD8 $\mathrm{T}$ cells may kill keratinocytes expressing E7 protein. Using a live-cell imaging-based killing assay, we co-cultured primary keratinocytes from mice expressing $\mathrm{E} 7$ from the keratin-14 promoter $(\mathrm{E} 7 \mathrm{KC})$, or from non-transgenic mice (B6KC), loaded with OVA, and $\mathrm{EGFP}^{+} \mathrm{CD} 8^{+}$effector $\mathrm{T}$ cells from OVAimmunized mice. These studies allowed us to examine the interactions between targets and effectors during the attachment and killing process and the kinetics of killing. E7KC were more susceptible to killing by CD8 $\mathrm{T}$ cells than their non-transgenic counterparts, however, it was apparent that effectors were using a different set of mechanisms to achieve target death. Additionally, E7KC themselves produced proteins such as FasL and PD-L1, lethal to cytotoxic $\mathrm{T}$ cells. Recently, utilizing an antiCD40 antibody to elicit immunization against HPVE6/E7 successfully primed CD8 T cells to kill papillomavirusrelated tumor cells in vitro [17]. Our data suggest that enhancement of effector function may be achieved by suppression of immune-inhibitory proteins.

\section{RESULTS}

\section{E7 expression alters the kinetics of keratinocyte killing}

We investigated the effects of expression of HPV E7 oncoprotein by primary keratinocytes (KC) on their susceptibility to killing by CD8 T cells. K14.E7 mice (E7), derived from C57/B6 mice (B6), express HPV E7, a major oncoprotein in HPV-related cervical cancer, from the keratin-14 promoter. Thus HPV E7 is expressed in these mice predominantly by keratinocytes. We isolated primary keratinocytes from $\mathrm{E} 7$ mice, or from B6 mice, loaded them with SIINFEKL peptide, the TCR epitope of OVA, and co-cultured with CD8 OT-I T cells, which have a TCR receptor specific for SIINFEKL presented by $\mathrm{H}-2^{\mathrm{b}}$. We found the total CTL-mediated killing of E7expressing and non-transgenic $\mathrm{KC}$ to be the same over 30 hours (Figure 1A), which was consistent with other studies [19]. However, examining the kinetics of killing, B6KC exhibited specific "lag" period before target cell death (Figure 1A) which we have seen previously [18], while E7-expressing $\mathrm{KC}$ did not exhibit any lag period before death (Figure 1A), implying these cells may have altered killing kinetics. When loaded with the same dose of cognate peptide antigen, E7KC were killed earlier than non-transgenic cells (Figure 1B). The rate of $\mathrm{KC}$ death in monocultures and in co-cultures without peptide was similar between $\mathrm{E} 7 \mathrm{KC}$ and $\mathrm{B} 6 \mathrm{KC}$, less than $7 \%$ over 30 hours (Figure 1C), showing E7 expression does not confer longevity on $\mathrm{KC}$ in culture. These data indicate that E7expressing $\mathrm{KC}$ remain susceptible remain susceptible to killing by antigen-specific CD8 T cells, but possibly by different mechanisms to non-transgenic $\mathrm{KC}$.

\section{Apoptosis of E7-expressing KC can follow a caspase- 3 independent pathway}

Both granule-mediated killing and Fas-mediated killing, the two primary contact dependent mechanisms used by CTL to kill their targets, predominantly involve activation of intracellular caspases, leading to activation of caspase 3 and resulting in cell death [20]. We investigated whether E7 expression altered the susceptibility of $\mathrm{KC}$ to be killed by caspase dependent mechanisms. Co-cultures of $\mathrm{KC}$ and CTL in the presence of FLIVO-SR dye that fluoresces red upon activation of intracellular caspases were treated with Z-DEVD-FMK, a specific inhibitor of caspase-3. Non-transgenic KC showed no progression to apoptosis as indicated either by cell morphology or by color change (Figure 1D, Supplementary Video 1). E7KC also had a marked reduction in the rate of apoptosis. However, around $35 \%$ of E7KC became apoptotic by color change and by morphology $(\mathrm{p}<0.05)$ (Figure 1D, E). Inhibition of caspase-3 did not affect duration of targetCTL attachment, which was similar in both E7 and B6KC 
in the presence of the caspase inhibitor (Figure 1F). We conclude that $\mathrm{E} 7 \mathrm{KC}$, but not $\mathrm{B} 6 \mathrm{KC}$, are susceptible to apoptosis by caspase- 3 independent mechanisms.

\section{E7-expressing KC can be killed by perforin- independent mechanisms}

Antigen-specific killing by CD8 effector cells classically occurs by granule-mediated mechanisms, which involve perforin-dependent delivery of granzymes to the target cell following direct CTL-target cell contact. To determine whether perforin is important in mediating KC killing by CD8 T cells, we immunized EGFP Prf1 ${ }^{-/}$or EGFP B6 mice with SIINFEKL and isolated CD8 T cells, further culturing them with SIINFEKL peptide for three days to generate perforin-deficient or perforin-competent antigen-specific $\mathrm{EGFP}^{+} \mathrm{CD}^{+}$CTL of comparable activation status as assessed by CD44 and $\mathrm{CD} 62 \mathrm{~L}$ expression (Figure 2A, B). These effector cells were cocultured with SIINFEKL-loaded E7KC or B6KC to assess target cell killing. In the absence of perforin, killing of non-transgenic $\mathrm{KC}$ was abrogated to baseline levels, while E7KC targets remained partially susceptible to CTLmediated killing suggesting perforin was not necessary for killing of E7-expressing $\mathrm{KC}(\mathrm{p}=0.02)$ (Figure 2C, D).

There was a marked reduction in the duration of attachment of effector cells to $\mathrm{KC}$ targets in the absence of perforin regardless of E7 expression (Figure 2E). Perforin- deficient CTL made numerous short-duration attachments to $\mathrm{KC}$ targets, lasting less than $60 \mathrm{~min}$, before detaching without causing target cell death. However, when perforindeficient CTL killed E7-expressing KC, they did so after an average attachment time of $18.4 \mathrm{~h}( \pm 4.2)$, compared with $13.3 \mathrm{~h}( \pm 3.6)$ for perforin-competent CTL $(\mathrm{p}=0.04)$, suggesting attachment time is relevant to the mechanism of target cell killing. Expression of E7 by $\mathrm{KC}$ did not affect $\mathrm{T}$ cell death rates (Figure $2 \mathrm{~F}$ ).

\section{E7KC are killed by TNF $\alpha$-dependent and IFN $\gamma$ - independent mechanisms}

Activated CD8 T cells produce TNF $\alpha$ and IFN $\gamma$ that contribute to their cytotoxic function. We inhibited TNF $\alpha$ by incubating co-cultures of target and antigen-loaded effector cells with anti-TNF $\alpha$ inhibitory antibody. AntiTNF $\alpha$ antibody completely abrogated killing of both E7expressing and non-transgenic KC (Figure 3A), without affecting duration of cell-to-cell attachment (Figure 3B) implying CD8 T cells depend on TNF $\alpha$ to kill target $\mathrm{KC}$. Inhibition of TNF $\alpha$ had no effect on death of T cells in the co-culture (Figure 3C). Inhibition of IFN $\gamma$, on the other hand, inhibited killing of $\mathrm{B} 6 \mathrm{KC}$, and partially inhibited killing of E7KC (Figure 3D) (B6 cf. E7 p<0.001; E7 isotype $\mathrm{cf}$. anti-IFN $\gamma \mathrm{p}=0.016)$, also without affecting duration of effector cells attachment to targets (Figure 3E). Inhibition of IFN $\gamma$ inhibited T cell death also in co-culture
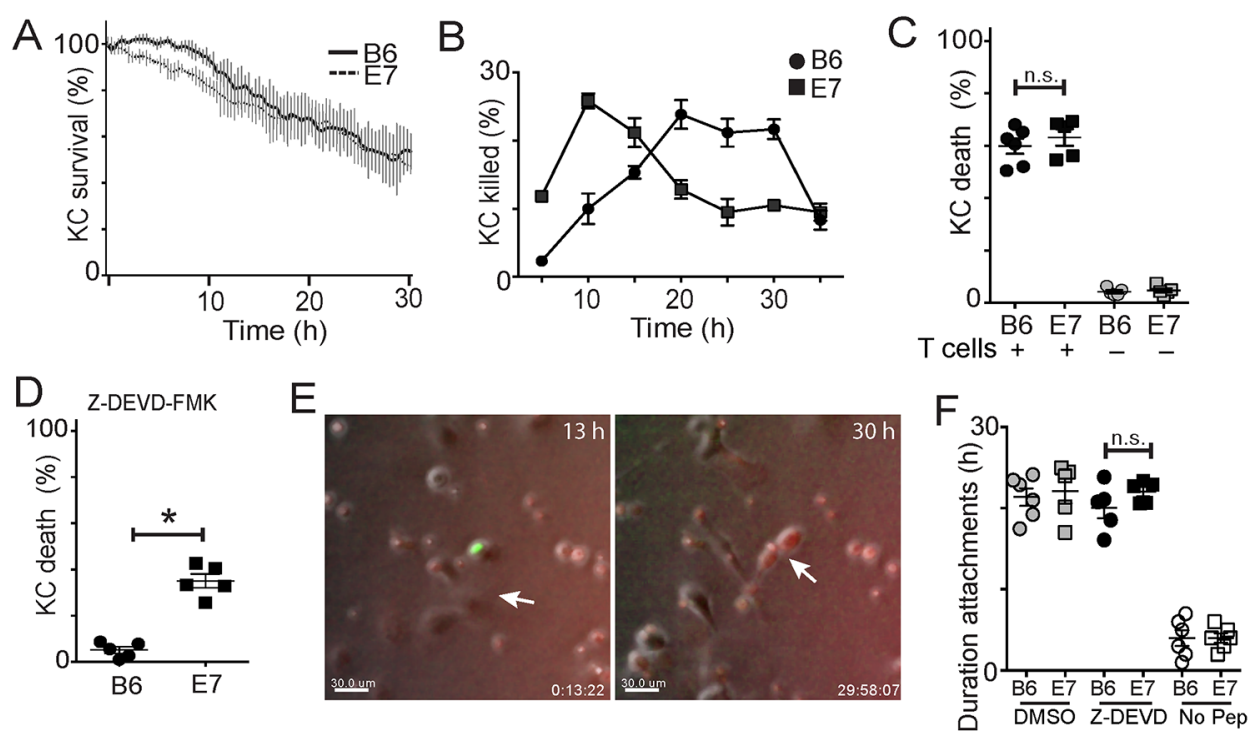

Figure 1: E7 expression by keratinocytes alters their susceptibility to killing by CTL. Primary KC were isolated from B6 or E7 transgenic mice and loaded with SIINFEKL peptide. EGFP ${ }^{+}$OT-1 T cells were isolated and co-cultured with skin cells, with indicator dye for activated caspases. (A) KC survival over 30 hours of co-culture. Average of 4 experiments shown, error bars represent SD. (B) The percentage of $\mathrm{KC}$ deaths at 5 hour intervals was determined by counting newly dead cells at each time point and expressing as a fraction of the total number of cells in each frame. (C) KC death at 30 hours in co-culture with effector cells (black) or in monoculture (grey). (D) KC were incubated with Z-DEVD-FMK or DMSO (Mock) 60 minutes before and during co-culture; death assessed at $30 \mathrm{~h}$. (E) CTL and KC co-cultures at $13 \mathrm{~h}$ showing attachment of CTL (green) to KC (arrow), and at $30 \mathrm{~h}$ showing early apoptosis of KC as indicated by red color change. Bar is $10 \mu \mathrm{m}$. See also, Supplementary Video 1. (F) Duration of attachments of E7-expressing (E7) or non-transgenic (B6) KC with CTL while incubated with DMSO (mock), Z-DEVD-FMK, or without peptide loading. ( ${ }^{*} \mathrm{p}<0.05$; n.s. not significant). 
with $\mathrm{B} 6 \mathrm{KC}$, but not with $\mathrm{E} 7 \mathrm{KC}$, attributable to reduced antigen-induced cell death in the $\mathrm{B} 6 \mathrm{KC}-\mathrm{T}$ cell co-cultures (Figure 3F).

To confirm the inhibitory antibodies were acting on the CTL, rather than on the target cells, we pre-incubated the CTL with inhibitory antibody for 4 hours prior to coculture with effector T cells. Inhibition of TNF $\alpha$ on CTL alone inhibited killing to a similar degree to treatment of co-cultures (Figure 3G). Inhibition of IFN $\gamma$ on CTL, while it markedly inhibited killing of B6 cells, only partially inhibited killing of E7-expressing $\mathrm{KC}$ (Figure 3H), suggesting that IFN $\gamma$ was not sufficient or necessary for CTL killing of E7-expressing $\mathrm{KC}$.

\section{E7 expression alters KC susceptibility to CD8 T cell killing by Fas/FasL}

Fas-FasL interaction is a major mechanism of interlymphocyte fratricide and CTL can express both Fas and FasL on their surface. Expression of Fas by tissue cells can be bound by CTL-related soluble or membrane-bound FasL resulting in target cell apoptosis, and may be an important mechanism of killing of tumor cells [21]. It is not known how E7 expression by keratinocytes affects their susceptibility to killing by the Fas/FasL system.

We incubated KC-CTL co-cultures with inhibitory antibody to Fas, or to Fas-L, both of which resulted in a significant, but not complete, inhibition of death of B6KC (Figure 4A and 4E; $p=0.046$ anti-Fas c.f. Isotype, $p=0.049$ anti-FasL c.f. Isotype). Inhibition of Fas and FasL also appeared to abolish the characteristic lag period before killing in these cells (Figure 4B, F). Inhibition of Fas or FasL reduced the duration of cell-to-cell attachment of both wild type and E7 transgenic KC (Figure 4C, G). Paradoxically, inhibition of either Fas or FasL caused a significant increase in killing of E7-expressing $\mathrm{KC}$ (Figure 4A, E; $p<0.05$ anti-Fas or anti-FasL c.f. Isotype). As CTL also express Fas, we examined the death rate of CD8 T cells in the co-cultures. With inhibition of either Fas or FasL, CTL death rate was significantly lower in co-cultures with E7KC, but not B6KC (Figure 4D, H), suggesting increased availability of cytotoxic $\mathrm{T}$ cells may be the mechanism by which Fas/FasL inhibition enhanced E7KC killing in this assay.

Therefore we examined E7KC and $\mathrm{B} 6 \mathrm{KC}$ to determine whether E7 expression increased the expression of Fas or
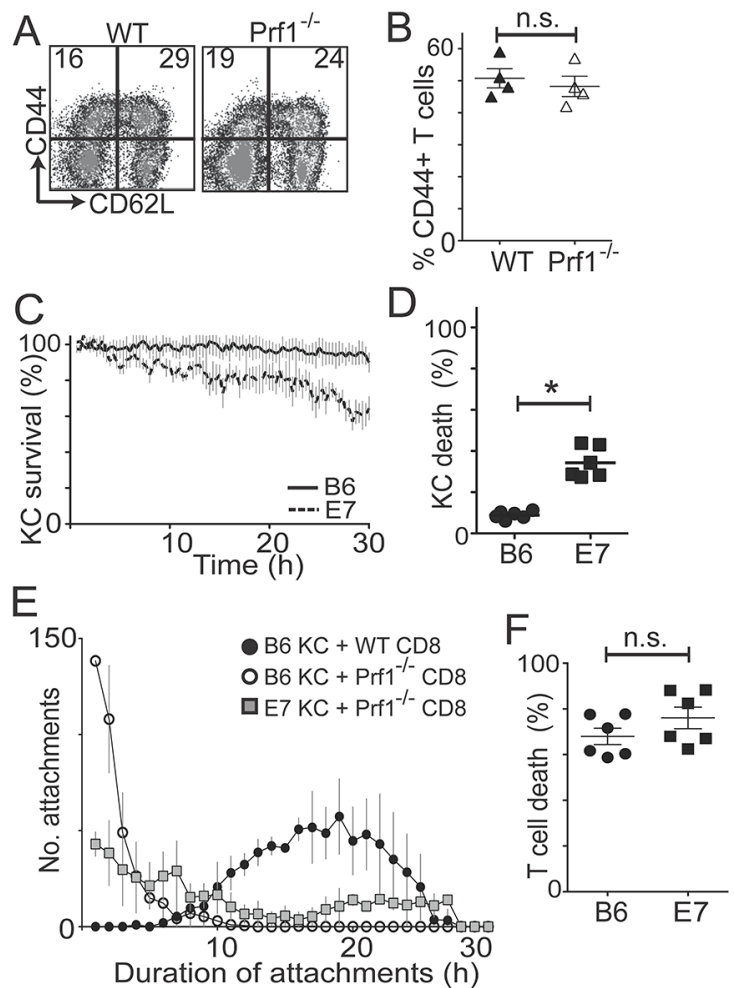

Duration of attachments (h)

Figure 2: CD8 T cells kill E7KC by perforin-independent mechanisms. In vivo and in vitro activated OVA-specific EGFP Prfcompetent and EGFP ${ }^{+} \mathrm{Prfl}^{-/} \mathrm{CD} 8 \mathrm{~T}$ cells were added to KC primary cultures. (A) Flow cytometry of wild-type (WT) and perforindeficient $\left(\mathrm{Prfl}^{-/}\right)$CD8 T cells pre-gated on size and granularity, and CD8 expression. (B) Percentage of CD44 cells after gating. Results of 4 independent CD8 harvests. (C) Primary KC from E7 and B6 mice were loaded with SIINFEKL and co-cultured with GFP ${ }^{+}$Prf1 ${ }^{-/}$CD8 $\mathrm{T}$ cells. KC survival calculated as in Figure 1. (D) The final frames of movies were used to calculate percentage KC death over 30 hours. (E) Frequency distribution of the duration of attachments of effector cells to targets at 30-minute intervals. (F) Quantification of T cell death in co-cultures with antigen-loaded E7-expressing or non-transgenic $\mathrm{KC}$ at 30 hours. ( ${ }^{*} \mathrm{p}<0.05$; n.s. not significant). 
FasL on the surface of the cells. Flow cytometry of freshly harvested $\mathrm{KC}$ showed increased Fas and FasL expression on the surface of E7KC compared with wild type KC (Figure 4I, J). Confocal microscopy after five days in culture allowing protein expression and cell division to recommence, showed that, although variability in expression levels between cells in the same culture was evident as expected with cycling cells, there was a marked increase in surface expression of Fas and FasL in E7-transgenic KC (Figure 4K, M). Examination of the RNA expression of cultured $\mathrm{KC}$ confirmed up-regulation of Fas mRNA expression in E7KC compared with wild type cells (Figure 4L), although FasL mRNA expression was not up regulated suggesting, as have others, that its regulation is post-transcriptional [22] (Figure 4N).

These data allow the hypothesis that $\mathrm{E} 7 \mathrm{KC}$ are more susceptible to apoptosis via Fas on their cell surface, and that increased expression of FasL may allow E7KC to kill effector T cells.

\section{PD-L1 expression by E7-expressing $\mathrm{KC}$ is protective}

Epithelial cell expression of PD-L1 as with FasL expression, has been associated with resistance of tumors to $\mathrm{T}$ cell mediated killing. PD-L1 is expressed on many epithelial cells, usually affording immune protection, as interaction with PD-1 on activated T cells leads to down regulation of $\mathrm{T}$ cell function. We found that inhibition of PD-L1 in co-cultures of effector and target cells had little effect on killing of non-transgenic $\mathrm{KC}$ (Figure $5 \mathrm{~A} ; \mathrm{p}=0.15$ untreated c.f. anti-PD-L1 in B6KC), but promoted killing of $\mathrm{KC}$ expressing E7, suggesting up regulation of PD$\mathrm{L} 1$ as a result of $\mathrm{E} 7$ expression contributes to resistance to $\mathrm{CD} 8 \mathrm{~T}$ cell killing (Figure $5 \mathrm{~A} ; \mathrm{p}=0.016 \mathrm{E} 7$ c.f. B6; $\mathrm{p}=0.03$ untreated c.f. anti-PD-L1 in E7KC). Unlike FasL inhibition, PD-L1 inhibition did not affect the duration of CTL/target cell attachment (Figure 5B). As the reduced killing may have been the result of an increasing ratio of effectors to target cells as the culture progressed, we investigated whether $\mathrm{T}$ cells were failing to die in these treated co-cultures. Inhibition of PD-L1 markedly reduced the death rate of CTL in E7KC co-cultures, implying that some of the CD8 T cell death was attributable to PD-L1 expressed on the surface of transgenic KC (Figure 5C).

We investigated whether E7 expression on $\mathrm{KC}$ altered their expression of PD-L1. Freshly isolated E7transgenic KCs were subject to surface staining for PDL1. We saw a significant increase in the surface expression

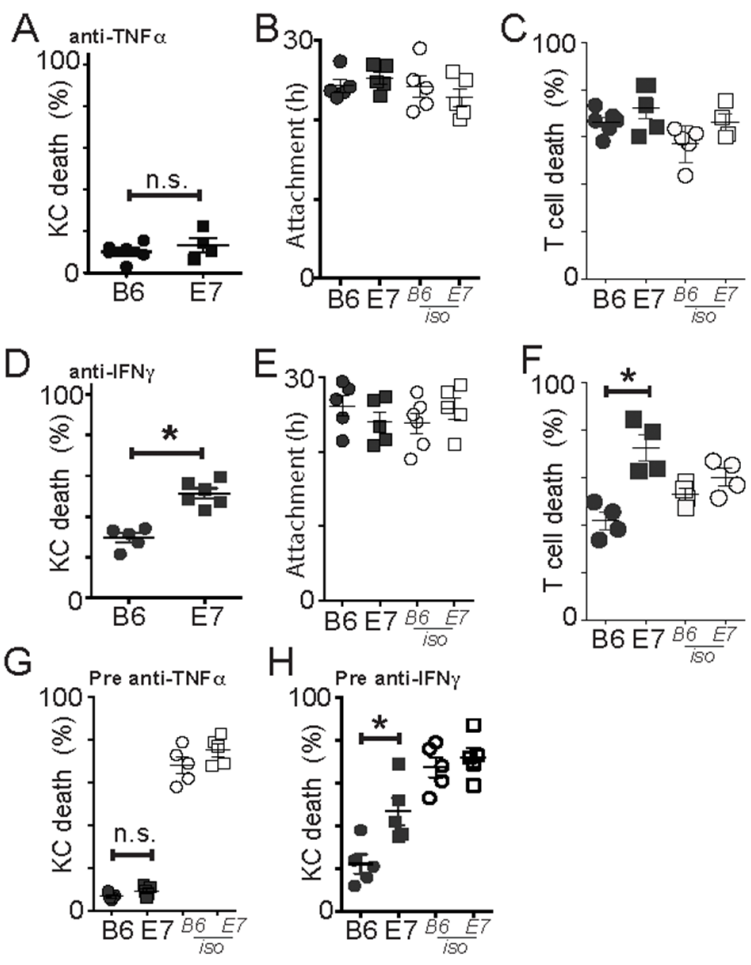

Figure 3: Perforin-competent CD8 effector T cells require TNF $\alpha$ but not IFN $\boldsymbol{\gamma}$ for cytotoxic function. EGFP ${ }^{+} \mathrm{OT}-1 \mathrm{~T}$ cells were incubated with KC loaded with SIINFEKL. (A-C) An inhibitory antibody to TNF $\alpha$ was added to the KC before and during co-culture. $\mathrm{KC}$ death (A), duration of attachment of effectors to targets (B) and death of effector cells (C) with anti-TNFa or isotype control antibody. (D-F) Anti-IFN $\gamma$ antibody was added to KC before and during co-culture. (D) KC death, duration of attachment (E) of effectors to targets and effector cell death (F) with anti-IFN $\gamma$ or isotype control antibody. (G-H) Effector cells were pre-treated with antibody against TNF $\alpha$ (E) or IFN $\gamma(\mathrm{F})$ before co-culture with target KC. Averages of 5 imaging sites of duplicate wells are shown as a single dot. Each dot is one separate experiment. Error bars are SEM. $\left({ }^{*} \mathrm{p}<0.05\right)$. 
of PD-L1 by flow cytometry in these cells (Figure 5D). RT-PCR studies of cultured $\mathrm{KC}$ at 7 days showed marked increase in PD-L1 RNA expression among E7KC compared with non-transgenic cells (Figure 5E).

\section{Hierarchical killing mechanisms used by CTL to kill E7-expressing KC}

CD8 T cells have been shown to utilize different mechanisms of cytotoxicity in a hierarchical, tissuedependent manner [23]. In order to investigate how E7 oncoprotein expression affected the hierarchy of mechanisms used in killing $\mathrm{KC}$, we now combined different combinations of the killing mechanisms recognized as being relevant to tumor killing to rank the importance of each. Not all combinations were included, particularly where the primary cytotoxic effect was so marked as to render any further effect immeasurable and irrelevant.

We co-cultured primary B6 or E7-expressing $\mathrm{KC}$ loaded with SIINFEKL with OVA-primed effector cells from perforin-competent B6 mice or from perforindeficient $\mathrm{Prfl}^{-/-}$mice, and inhibited Fas or FasL. Inhibition of the Fas pathway abrogated the non-perforin mediated
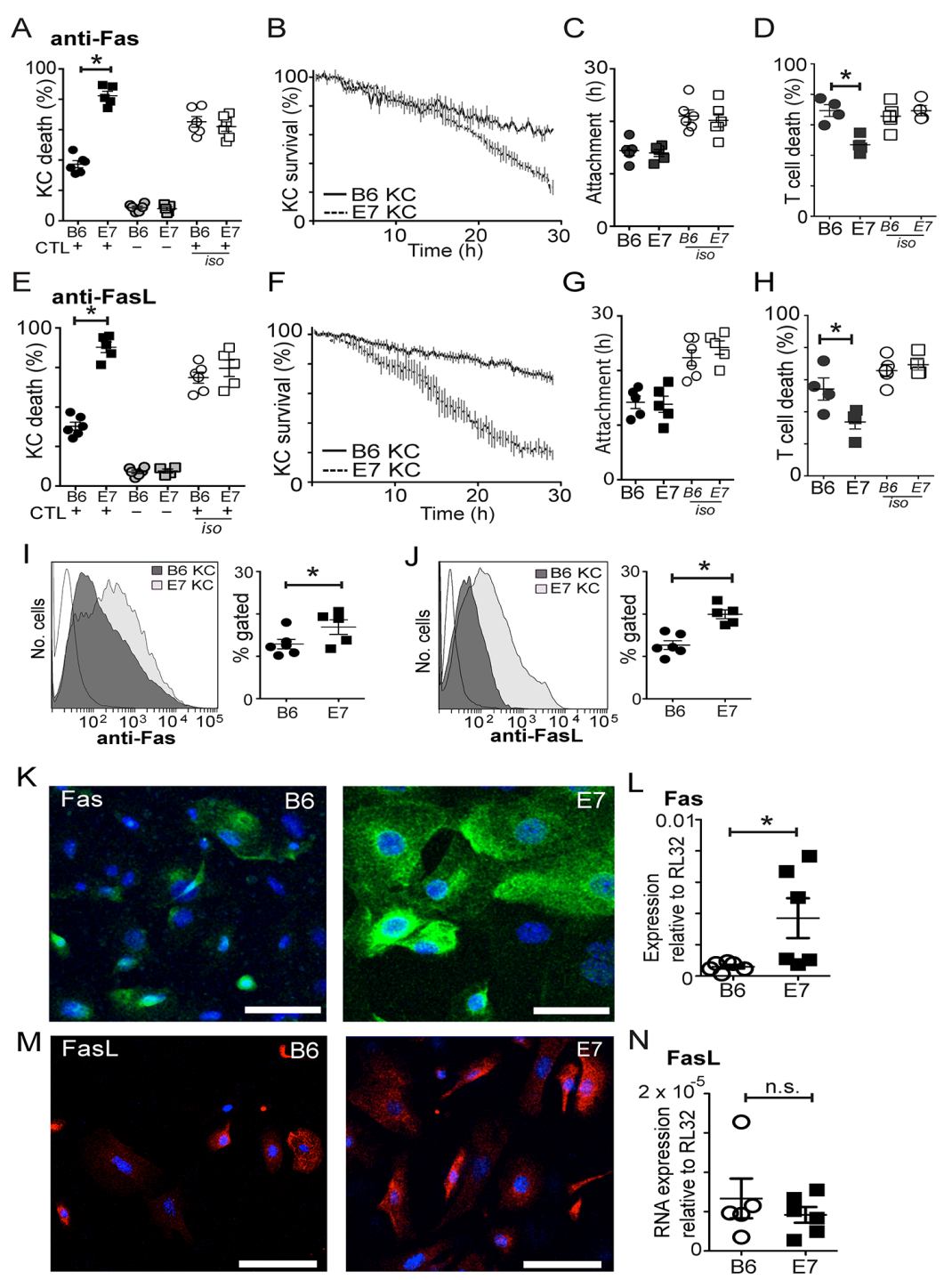

Figure 4: CD8 T cells utilize Fas/FasL to kill E7 expressing KC. Co-cultures of effector cells and SIINFEKL-loaded KC were treated with inhibitory antibody to Fas (A-D) or FasL (E-H) or isotype control antibodies (iso). (A, E) Death of KC in co-culture (black) or monoculture controls (grey). (B, F) Survival kinetics of KC-effector co-cultures. (C, G) Duration of effector-KC attachment. (D, H) $\mathrm{T}$ cell death rate. Freshly-derived primary KC were examined for Fas (I) or FasL (J) expression by flow cytometry. Gating delineated living cells that were CD45 negative. Each value represents one mouse. (K, M) Confocal micrograph (maximal intensity projection) of primary KC cultured for 5 days and stained for surface expression of Fas (green) (K) or FasL (red) (M). (L, N) Primary KC were cultured for 5 days and cell lysates were harvested for RNA extraction. RT-PCR for Fas (L) or FasL (N) mRNA was performed comparing expression to a house-keeping gene. Each value represents one mouse. ( ${ }^{*} \mathrm{p}<0.05$; n.s not significant; bar is $\left.50 \mu \mathrm{m}\right)$. 
killing of E7-expressing $\mathrm{KC}$ seen in Figure 2 to levels similar to that of non-transgenic cells (Figure 6A, B). Fas had no protective effect on killing of E7KC in the absence of perforin.

Perforin-dependent B6KC killing, which was partially reduced by inhibition of PD-L1, was further reduced by inhibition of Fas. Similarly, the protective effect of PD-L1 on E7KC was not seen in the absence of perforin as inhibition of PD-L1 resulted in abrogation of perforin-independent killing in E7KC (Figure 6C).
Likewise, although TNF $\alpha$ inhibition of perforinsufficient $\mathrm{T}$ cells abrogated $\mathrm{KC}$ death, in perforindeficient co-cultures, the reduction in $\mathrm{KC}$ death was much less, implying that perforin-mediated killing was more dependent on TNF $\alpha$ than perforin-independent killing. Additional inhibition of Fas was not protective of E7KC death by perforin-sufficient CTL and did further impede killing by perforin-deficient CTL. (Figure 6D).

IFN $\gamma$ has been shown to enhance cytotoxic killing of target cells by inducing antigen expression and increased
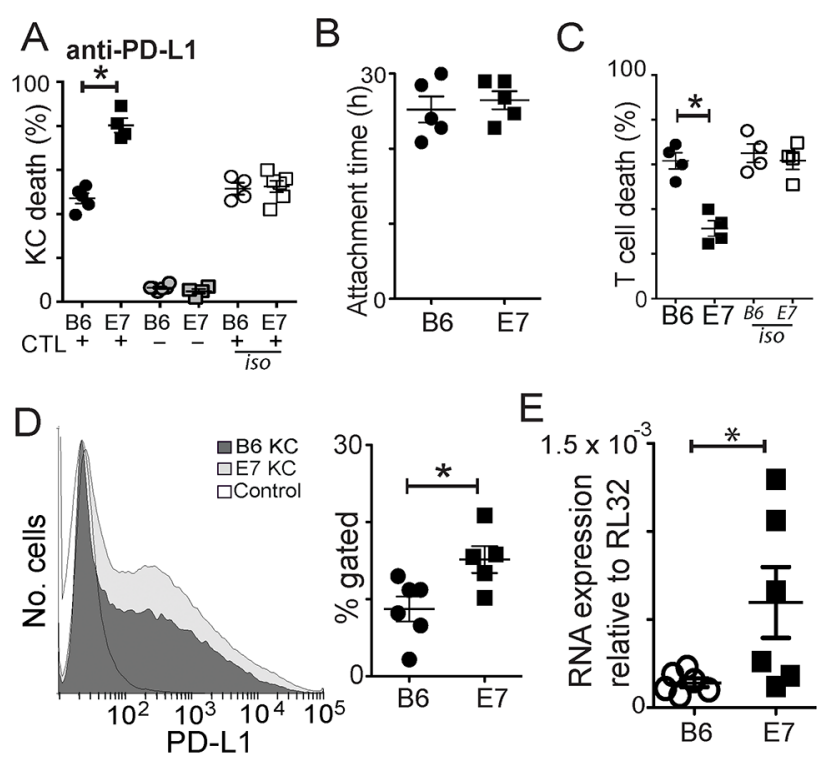

Figure 5: Increased levels of PD-L1 expression by E7KC is protective. Co-cultures of CTL and SIINFEKL-loaded B6KC or E7KC were treated with anti-PD-L1 antibody or isotype control antibody. (A) Death of KC in co-culture with effectors (black) or as monocultures (grey), or in co-cultures without PD-L1 inhibition (white). (B) CTL-target attachment duration. (C) CTL death in co-cultures. (D) Flow cytometry of primary $\mathrm{KC}$ harvested as in Figure 4E, and stained for PD-L1 expression using the same gating strategy. Isotype control is also shown. (E) Primary KC were cultured for 5 days and cell lysates were harvested for RNA extraction and subject to RT-PCR for PD-L1 mRNA quantification. Each value is one mouse. ( $\left.{ }^{*} \mathrm{p}<0.05\right)$.
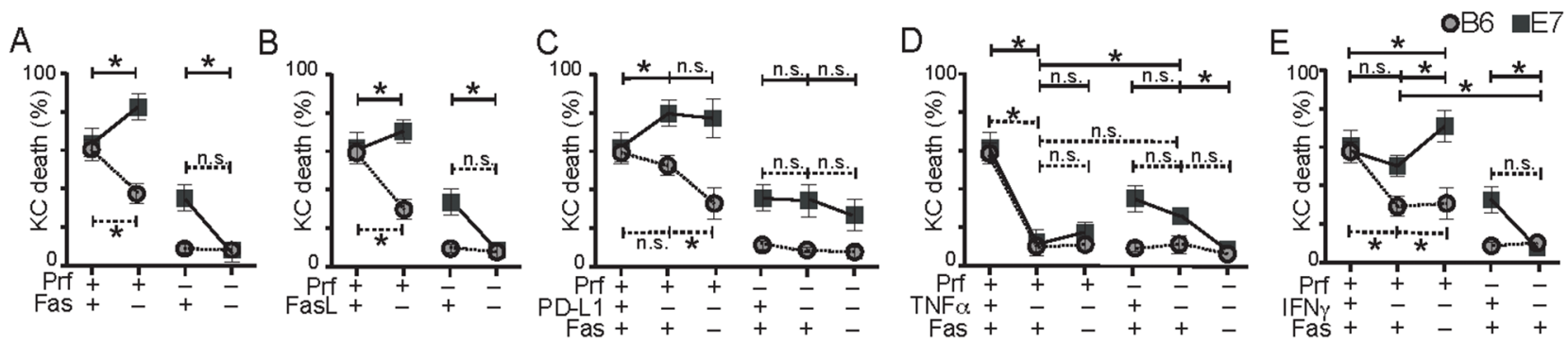

Figure 6: Hierarchical killing of $\mathbf{K C}$ by $\mathbf{C T L}$ is altered by $\mathbf{E} 7$ expression. T cell killing mechanism hierarchy was investigated by inhibition of multiple pathways during co-culture of primary non-transgenic KC (B6) or E7-expressing KC (E7) loaded with constant amount of peptide and perforin-competent or Prf $1^{-/}$effector CD8 T cells. Co-cultures were incubated with anti-Fas (A), or anti-FasL (B) inhibitory antibody. (C) Co-cultures of effector and target cells were incubated with anti-PD-L1 inhibitory antibody, with or without Fas inhibition. (D) Co-cultures were treated with anti-TNF $\alpha$ antibody with or without Fas inhibition. (E) Co-cultures were treated with antiIFN $\gamma$ with, or without, Fas inhibition. Average values of five imaging sites of duplicate wells for each experiment are shown as one dot. $\left({ }^{*} \mathrm{p}<0.05\right)$ Data from single inhibitor experiments Figure 2-5 have been reshown in these graphs for ease of comparison. Note that the ' + ' indicates the functional presence of the particular cytokine while '-' indicates its absence by knock-out or by antibody (e.g. If Fas is present, there is a ' + ', while Fas inhibition with antibody is indicated by '-'). 
cytokine production. In immune-mediated killing of E7expressing $\mathrm{KC}$, its role in vivo appears to be inhibitory [24]. In vitro, inhibition of IFN $\gamma$ did not significantly affect CTL killing of E7KC (Figure 6E), but inhibiting Fas in this environment increased E7 target cell loss, suggesting the protective effect of Fas on E7 killing is independent of IFN $\gamma$. In the absence of perforin, on the other hand, inhibition of IFN $\gamma$ abrogated killing. These data suggest IFN $\gamma$ plays a role in the perforin-independent killing of E7KC.

Based on these tests, we ranked the mechanisms of killing used by CTL to achieve target cell death of $\mathrm{B} 6$ and E7KC. CTL killing of non-transgenic $\mathrm{KC}$ relies predominantly on perforin and appears to be licensed by TNF $\alpha$. Further down the hierarchy, but playing an important role are IFN $\gamma$ and the Fas/FasL system, while PD1/PD-L1 system plays no role in KC killing. TNF $\alpha$ plays a key role among the mechanisms CTL used to kill E7KC. Ranked below this, and equally significant in vitro are IFN $\gamma$ and perforin, while the Fas/FasL system and PD1/PD-L1 system offer some protection for E7KC against these mechanisms. The percentage of killing of E7KC that is perforin-independent may be due to IFN $\gamma$ or the Fas/FasL system, while TFN $\alpha$ plays only a minor role in this system (Figure 7).

\section{DISCUSSION}

CD8 T cells, the primary effector cells in tumor eradication, utilize a variety of seemingly overlapping and redundant mechanisms to effect target cell death, both contact-dependent and contact independent, a trait particularly important to their anti-viral functions [25]. The relationships between these redundant mechanisms are highly complex and likely offer an evolutionary advantage. Here we show that these mechanisms can be used hierarchically in response to oncogene expression. This study does not examine the effect of priming and the response of the $\mathrm{T}$ cell to the specific antigen expressed by the target cell, rather it examines how expression of the oncogene alters protein expression within the cell to require effector $T$ cells to utilize different mechanisms of killing in order to effect target cell death.

CD8 $\mathrm{T}$ cells are known to predominantly use perforin to kill target cells. Earlier studies identified TNF $\alpha$-mediated killing mechanisms as equally significant in achieving target cell death, in both infectious and noninfectious models $[26,27]$, which we confirm here. We also found that with non-oncogene expressing $\mathrm{KC}$, IFN $\gamma$ and Fas/FasL were less critical to achieve target cell death, and supplemented the primary mechanisms. Fas and IFN $\gamma$ have been reported to be more important in killing pancreatic beta cells in T-cell dependent murine models of diabetes mellitus [28] although TNF $\alpha$ assistance was essential [23], as was also confirmed in this model.

The factors that determine the choice of mechanism used by CD8 effector cells to achieve target cell death remain unclear. Target cell type likely plays an important part, as death is determined by the concentration of specific receptors on the target cell surface such as FasL, IFN $\gamma$ R and negative ligands such as Fas and PD-L1. Keratinocyte

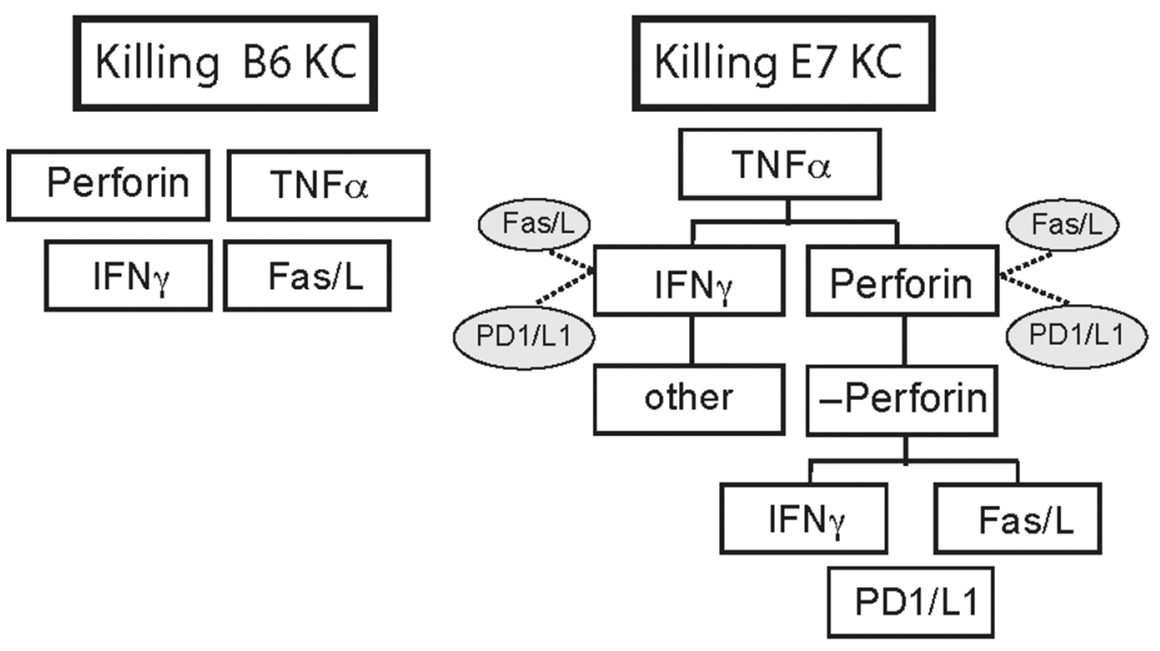

Figure 7: E7 expression by KC alters hierarchy of killing mechanisms used by CTL. Putative differences in the hierarchy of killing mechanisms used by CTL to kill KC expressing E7 compared with non-transgenic B6KC targets as modeled by in vitro killing studies in this study. Cytokines inhibitory to a specific killing mode are indicated by dotted lines. Without oncogene expression, B6KC were killed predominantly by perforin and TNF $\alpha$ mediated mechanisms, both of which were essential, while Fas/FasL and IFN $\gamma$ were less important modes of killing. PD-L1 is not expressed in B6KC, and blockade had no effect on killing, and this has been excluded from the diagram. With expression of E7 oncogene, E7KC still require TNF $\alpha$ as essential for killing. Less significantly, IFN $\gamma$ and perforin contribute to killing targets. IFN $\gamma$-independent killing does take place, but it appears not to be mediated by any of the processes we examined here. Perforin-independent killing is reliant on Fas/FasL or on IFN $\gamma$. PD1/L1 contributes to target cell death perforin-independent killing, but along with Fas/FasL, inhibits killing by IFN $\gamma$ and perforin in perforin-sufficient $\mathrm{T}$ cells. 
susceptibility to non-perforin mediated killing is markedly up-regulated in the absence of PD-1/PD-L1 interaction [29], suggesting that redundant killing mechanisms are preferentially up-scaled when primary mechanisms are not available. Additionally, the inflammatory environment and cytokine milieu may play a key role in determining the actions of infiltrating effector cells. Extreme inflammatory environments lead to large amounts of locally produced $\mathrm{TNF} \alpha$ and IFN $\gamma$ which, in addition to being cytotoxic to $\mathrm{KC}$ directly, also up-regulate Fas-mediated $\mathrm{KC}$ death [30, 31]. The strength of the signal to $T$ cells has also been implicated in determining the mechanism of cell death, with high-affinity ligands leading to perforin-mediated killing while low affinity ligands utilize slower perforinindependent pathways [32]. Additionally, the use of perforin and Fas by CTL has been associated with strength of priming in antigen-specific killing and Fas expression may improve perforin-mediated killing [33, 34].

Pathogenic organisms, such as viruses, adapt their host cell to avoid being killed rapidly by perforin, which may leave them more susceptible to slower Fas/ FasL interaction for eradication [35], thus giving the organism time to replicate and disseminate. In this study, utilization of Fas/FasL resulted in markedly increased contact time between effector and target cells. In the E7 transformed $\mathrm{KC}$ with its increased rate of replication, this may represent a mechanism for immune cells to escape killing by Fas. We speculate that the prolonged contact time required for Fas-mediated killing may promote modalities of cellular escape by target cells during this phase of attachment such as alteration of membrane dynamics during mitosis. The effects of target cell mitosis on immunological killing mechanisms is unknown and we suggest the utilization of imaging techniques is assessing effector-target contact in tumors is a useful in assessing this further. In addition, FasL expression on endothelial cells has been shown to delay $\mathrm{T}$ cell migration into tumours and may have an effect on $\mathrm{T}$ cell motility which we have previously shown is directly related to tumour killing ability by these cells $[18,36]$.

HPV E7 expression confers changes upon host keratinocytes that may have had a growth advantage for the virus which persist upon transformation. In immortalized cell lines and transformed KC, E7 expression confers resistance to the direct cytostatic effects of TNF $\alpha$ possibly by the upregulation of cell cycling and replication due to the action of E7 on the retinoblastoma gene [10, 37]. We did not assess $\mathrm{KC}$ replication in our model, but suggest additionally that oncogenes such as E7 may alter the expression levels of surface markers reliant on TNF $\alpha$ stimulation, such as Fas and IFN $\gamma \mathrm{R}$, which are required for CD8 T cell mediated killing. This is also supported by evidence that the addition of TNF $\alpha$ to tumor cells increases their susceptibility to Fas-mediated killing by effector cells [38].

HPV-related cervical cancer and head and neck cancers are associated with increased expression of PD-
L1, which is associated with dysfunction of the $\mathrm{T}$ cell immune response to these tumors [16, 39]. We show here that $\mathrm{E} 7$ expression on $\mathrm{KC}$ is sufficient to up-regulate of these negative receptors resulting in both $\mathrm{KC}$ protection and in increased death of effector cells, promoting a fightback response. Tumors are associated with a infiltration of $\mathrm{T}$ cells displaying varying degrees of exhaustion [40], characterized by low levels of perforin and IFN $\gamma$ expression, and increased expression of negative regulators such as PD1. Thus perforin-independent mechanisms of T cell killing become important in maintaining some degree of anti-tumor activity. Interestingly, IFN $\gamma$-independent killing of E7KC took place that is not dependent on any of the other methods of killing we have examined here, emphasizing that CD8 T cells have an extensive armamentarium of killing, and we have explored only some of the major ones in this study. Molecules such as Tim-3 have shown increasing promise as therapeutic targets and remain to be explored [41].

Understanding the changing nature of susceptibility to immune-modulated killing mechanisms due to oncogene expression holds the key to optimizing immunotherapy for HPV-related cancers. Using a protease inhibitor to sensitize tumors to apoptosis resulted in enhanced IFN $\gamma$ production, increased Fas expression and improved tumor lysis in vivo [42]. Likewise, inhibition of PD1/L1 reduces $\mathrm{T}$ cell death and improves eradication of HPV-related tumors in immunomodulatory therapy [43]. Recently, an anti-CD40 based vaccine against E7 was able to prime T cells to kill HPV-related tumor cells, suggesting that once cytotoxic T cells are primed against E7 targets, their killing may be optimized to achieve strong tumorcidal efficacy [17]. Additionally, chemotherapeutic agents may be immunologic sensitizers to immunotherapy, modulating cancer targets for better recognition and killing [44]. Optimization measures could include a combination of blockade of negative regulators Fas/FasL and PD1/L1, along with cell sensitization therapies to improve IFN $\gamma$ and perforin-mediated killing. Further investigation of IFN $\gamma$-independent killing of E7-expressing $\mathrm{KC}$ may lead to more therapeutic targets.

In this study, we employed a minimalist model in vitro using primary murine cells to examine the relative importance of several redundant killing mechanisms used by cytotoxic $T$ cells in effecting tumour cell death. These mechanisms may reflect only part of the interactions in vivo in human disease in which levels of inflammatory cytokines and variable expression of cognate antigen play important roles.

\section{MATERIALS AND METHODS}

\section{Mice}

All experiments were approved by the University of Queensland animal ethics committee. K14.E7 mice 
from a B6 background were bred in-house. Rag1 $1^{-/-}$mice were purchased from the Animal Resource Centre, Perth, Australia. B6.Nzeg mice express a nuclear-localised enhanced green fluorescent protein (EGFP) and were provided by K. Matthaei, Australian National University. B6.Prf1 ${ }^{-/}$mice were bred with B6.Nzeg mice to generate $\mathrm{Prfl}^{-/}$. Nzeg mice, also expressing EGFP.

\section{Reagents}

Anti-CD44, anti-IFN $\gamma$, anti-CD8, relevant isotype antibodies as well as inhibitory antibodies to Fas, FasL, $\mathrm{TNF} \alpha$, and INF $\gamma$ were purchased from BD Pharmingen. Anti-CD62L was from eBioscience. Recombinant IFN $\gamma$ was purchased from R\&D Systems. Z-DVED-FMK and ovalbumin (OVA) were purchased from Sigma. Media for cell culture and IL-2 was purchased from Invitrogen.

\section{Keratinocyte culture}

Primary KC were harvested from 3-4 day old E7 and B6 mice as described [13]. Keratinocytes were cultured in 24-well culture plates (allocating 12 wells to each $\mathrm{KC}$ type) in DMEM with 5\% fetal bovine serum for 24 hours before changing to Serum-Free Media supplemented with bovine pituitary extract and epidermal growth factor. The 24-well plate of $\mathrm{KC}$ was imaged when the cells were $70 \%$ confluent.

\section{Harvest of CD8 T cells}

$\mathrm{EGFP}^{+}$mice were immunised by subcutaneous injection with $50 \mu \mathrm{g}$ of OVA, and Quil A (20 $\mu \mathrm{g})$. Splenocytes were harvested one week later, and stained with anti-CD8, before FACS to obtain a $>98 \%$ pure population of $\mathrm{GFP}^{+} \mathrm{CD}^{+}$cells. These were further cultured for three days in the SIINFEKL peptide, the minimal CTL epitope of OVA, and IL-2 to further select for OVAspecific CD8 T cells.

\section{Co-culture}

C57 and E7KC were loaded with $1 \mu \mathrm{g} \cdot \mathrm{ml}^{-1}$ of SIINFEKL peptide for $60 \mathrm{~min}$ at $37^{\circ} \mathrm{C}$ once they reached $70 \%$ confluence in culture on 24 -well plates. $\mathrm{KC}$ were extensively washed in warm PBS before co-culturing with effector cells. We added $5 \times 10^{3} \mathrm{EGFP}^{+} \mathrm{CD}^{+} \mathrm{T}$ cellsper well into duplicate wells of keratinocytes, giving an approximate target:effector ratio of 10:1. Cells were imaged at $37^{\circ} \mathrm{C}$ with $5 \% \mathrm{CO}_{2}$ for $30 \mathrm{~h}$ in $50 \%$ serumfree medium, 45\% RPMI, 5\% fetal bovine serum, $5 \mathrm{ng}$. $\mathrm{ml}^{-1}$ IL-2 and 2\% SR-FLIVO solution. We included control wells of $\mathrm{KC}$ monocultures in each plate, as well as co-cultures without peptide loading, to assess baseline $\mathrm{KC}$ death and ensure there was no non-antigen specific killing as previously described [18]. Inhibitory antibodies or isotype control antibodies were added to the $\mathrm{KC}$ at the time of CTL addition unless stated otherwise. In pre-incubation experiments, $\mathrm{KC}$ were incubated with antibodies or isotype controls for $60 \mathrm{~min}$ and cells were then washed four times with media prior to the addition of CTL.

\section{Cell killing assay}

As previously, activation of intracellular caspases was noted by a color change in the cells mediated by cellpermeant SR-FLIVO red (courtesy of Immunochemistry Laboratories), as determined by image analysis software [18]. Rates of $\mathrm{KC}$ death of cells were determined by size $(>12 \mu \mathrm{m}$ for $\mathrm{KC}$ and $<10 \mu \mathrm{m}$ for T cells), and expressed as a percentage of number of cells of that type visible at time 0 . We used at least 3 fields of view per well of duplicate wells from at least 3 replicated experiments.

\section{RNA analysis}

Ear skin samples were lysed into RNase-free microtubes in $1 \mathrm{ml}$ of Trizol (Sigma) and RNA extracted according to manufacture's instructions. The RNA pellet was washed twice in 70\% ethanol and air-dried before resuspension and genomic DNA was then digested as per manufacturer (Qiagen). RNAs were quantified by nanodrop spectrophotometry. For retro-transcription, 500 ng of RNA combined with $25 \mathrm{mM} \mathrm{MgCl}_{2}, 25 \mathrm{mM}$ dNTPs, oligoDT, RNase inhibitor, and MuLV Taq polymerase in its buffer for $25 \mathrm{~min}$ at $25^{\circ} \mathrm{C}, 60 \mathrm{~min}$ at $42^{\circ} \mathrm{C}$ and $5 \mathrm{~min}$ at $95^{\circ} \mathrm{C}$. Samples were amplified using Sybr premix Taq II (TAKARA) on ABI7900 (Applied Biosystems) - 1x $30 \mathrm{~s}$ at $95^{\circ} \mathrm{C}, 45 \mathrm{x}\left(5 \mathrm{~s} 95^{\circ} \mathrm{C}\right.$ and $30 \mathrm{~s}$ at $\left.60^{\circ} \mathrm{C}\right)$, followed by $(15 \mathrm{~s}$ at $95^{\circ} \mathrm{C}, 60 \mathrm{~s}$ at $60^{\circ} \mathrm{C}, 15 \mathrm{~s}$ at $95^{\circ} \mathrm{C}$ ). Primers were designed using Integrated DNA Technologies.

\section{Immunofluorescence}

Cells for flow cytometry were prepared by trypsination of co-cultures, followed by viability staining, and then surface staining with anti-Fas or anti-FasL antibody or isotype-specific negative controls at $4^{\circ} \mathrm{C}$ before running on $\mathrm{BD}$ FacsCanto with Diva software. Semiquantitative analysis was determined only as a percentage of total cells by flow cytometry. For microscopy studies, co-cultures were performed on chamber slides, which were then harvested, fixed in $1 \%$ paraformaldehyde and stained for surface antigen expression.

\section{Microscopy}

Confocal microscopy was performed on a Zeiss Meta-510 confocal microscope using Zen software, with $\times 25$ oil-immersion objective lens. Time-lapse microscopy was performed on a Zeiss Axiovert 200M microscope with $\mathrm{a} \times 10$ objective lens. Images were acquired from five fields of view per well from duplicate wells every $12 \mathrm{~min}$ 
for $30 \mathrm{~h}$. Cells were maintained with humidification, in $5 \% \mathrm{CO}_{2}$, at $37^{\circ} \mathrm{C}$ during imaging by specialized enclosure built around the microscope.

\section{Image analysis}

Imaris software was used to de-convolve and analyze raw images, and generate movies. Death of $\mathrm{KC}$ and $\mathrm{T}$ cells was determined by caspase- 3 activation and resultant red color change. Statistical analysis was performed using Excel and Graphpad Prism. To prepare images for publication, cropping, a median filter $(3 \times 3)$, and minor contrast adjustments were made using Adobe Photoshop or Imaris.

\section{Statistics}

Data were collected from 5 sites each from duplicate wells and averaged giving a single value for each experiment, and experiments were repeated at least 3 times. We used the one-tailed Mann-Whitney test, or one-way ANOVA to compare non-parametric data. We accepted $\mathrm{p}<0.05$ as showing significant difference between groups.

\section{Author contributions}

PB conceived the questions, designed experiments, conducted experiments, analysed the data, prepared figures and wrote the manuscript. ASB conducted experiments, analysed data, prepared figures and wrote the manuscript. NW analysed data and wrote the manuscript. IHF analysed data and wrote the manuscript.

\section{ACKNOWLEDGMENTS}

IHF was supported by grants from National health and Medical Research Council of Australia Program Grant-569938, National Cancer Institute (NIH)-U01-015317, Australian Cancer Research Foundation. IHF and PB were supported by a Cancer Council Queensland research grant.

\section{CONFLICTS OF INTEREST}

The authors declare no conflicts of interest or competing financial interests.

\section{FUNDING}

IHF was supported by grants from National health and Medical Research Council ofAustralia Program Grant-569938, National Cancer Institute (NIH)-U01-015317, Australian Cancer Research Foundation. IHF and PB were supported by a Cancer Council Queensland research grant.

\section{REFERENCES}

1. Gooi Z, Chan JY, Fakhry C. The epidemiology of the human papillomavirus related to oropharyngeal head and neck cancer. Laryngoscope. 2016; 126: 894-900. https://doi. org/10.1002/lary.25767.

2. Bhat $\mathrm{P}$, Mattarollo SR, Gosmann C, Frazer IH, Leggatt GR. Regulation of immune responses to HPV infection and during HPV-directed immunotherapy. Immunol Rev. 2011; 239: 85-98. https://doi. org/10.1111/j.1600-065X.2010.00966.X.

3. Stanley MA. Epithelial cell responses to infection with human papillomavirus. Clin Microbiol Rev. 2012; 25: 215 22. https://doi.org/10.1128/CMR.05028-11.

4. Ovestad IT, Gudlaugsson E, Skaland I, Malpica A, Kruse AJ, Janssen EA, Baak JP. Local immune response in the microenvironment of CIN2-3 with and without spontaneous regression. Mod Pathol. 2010; 23: 1231-40. https://doi. org/10.1038/modpathol.2010.109.

5. Jaafar F, Righi E, Lindstrom V, Linton C, Nohadani M, Van Noorden S, Lloyd T, Poznansky J, Stamp G, Dina R, Coleman DV, Poznansky MC. Correlation of CXCL12 expression and FoxP3+ cell infiltration with human papillomavirus infection and clinicopathological progression of cervical cancer. Am J Pathol. 2009; 175: 1525-35. https://doi.org/10.2353/ajpath.2009.090295.

6. Cromme FV, Walboomers JM, Van Oostveen JW, Stukart MJ, De Gruijl TD, Kummer JA, Leonhart AM, Helmerhorst TJ, Meijer CJ. Lack of granzyme expression in $\mathrm{T}$ lymphocytes indicates poor cytotoxic $\mathrm{T}$ lymphocyte activation in human papillomavirus-associated cervical carcinomas. Int J Gynecol Cancer. 1995; 5: 366-73.

7. Dunn LA, Evander M, Tindle RW, Bulloch AL, de Kluyver RL, Fernando GJ, Lambert PF, Frazer IH. Presentation of the HPV16E7 protein by skin grafts is insufficient to allow graft rejection in an E7-primed animal. Virology. 1997; 235: 94-103. https://doi.org/10.1006/viro.1997.8650.

8. Aguilar-Lemarroy A, Gariglio P, Whitaker NJ, Eichhorst ST, zur Hausen H, Krammer PH, Rosl F. Restoration of p53 expression sensitizes human papillomavirus type 16 immortalized human keratinocytes to CD95-mediated apoptosis. Oncogene. 2002; 21: 165-75. https://doi. org/10.1038/sj.onc.1204979.

9. Sin JI. Suppression of antitumour protective cytotoxic $\mathrm{T}$ lymphocyte responses to a human papillomavirus 16 E7 DNA vaccine by coinjection of interleukin-12 complementary DNA: involvement of nitric oxide in immune suppression. Immunology. 2009; 128: e707-17. https://doi.org/10.1111/j.1365-2567.2009.03068.x.

10. Boccardo E. HPV-mediated genome instability: at the roots of cervical carcinogenesis. Cytogenet Genome Res. 2010; 128: 57-65. https://doi.org/10.1159/000290657.

11. Zhou F, Leggatt GR, Frazer IH. Human papillomavirus 16 E7 protein inhibits interferon-gamma-mediated 
enhancement of keratinocyte antigen processing and T-cell lysis. FEBS J. 2011; 278: 955-63. https://doi. org/10.1111/j.1742-4658.2011.08011.x.

12. Cordano P, Gillan V, Bratlie S, Bouvard V, Banks L, Tommasino M, Campo MS. The E6E7 oncoproteins of cutaneous human papillomavirus type 38 interfere with the interferon pathway. Virology. 2008; 377: 408-18. https:// doi.org/10.1016/j.virol.2008.04.036.

13. Leggatt GR, Dunn LA, De Kluyver RL, Stewart T, Frazer IH. Interferon-gamma enhances cytotoxic $\mathrm{T}$ lymphocyte recognition of endogenous peptide in keratinocytes without lowering the requirement for surface peptide. Immunol Cell Biol. 2002; 80: 415-24. https://doi. org/10.1046/j.1440-1711.2002.01105.x.

14. Basile JR, Zacny V, Munger K. The cytokines tumor necrosis factor-alpha (TNF-alpha ) and TNF-related apoptosis-inducing ligand differentially modulate proliferation and apoptotic pathways in human keratinocytes expressing the human papillomavirus-16 E7 oncoprotein. J Biol Chem. 2001; 276: 22522-8. https://doi.org/10.1074/jbc.M010505200.

15. Richards KH, Doble R, Wasson CW, Haider M, Blair GE, Wittmann M, Macdonald A. Human papillomavirus E7 oncoprotein increases production of the anti-inflammatory interleukin-18 binding protein in keratinocytes. J Virol. 2014; 88: 4173-9. https://doi.org/10.1128/JVI.02546-13.

16. Yang W, Song Y, Lu YL, Sun JZ, Wang HW. Increased expression of programmed death (PD)-1 and its ligand PD-L1 correlates with impaired cell-mediated immunity in high-risk human papillomavirus-related cervical intraepithelial neoplasia. Immunology. 2013; 139: 513-22. https://doi.org/10.1111/imm.12101.

17. Yin W, Duluc D, Joo H, Xue Y, Gu C, Wang Z, Wang L, Ouedraogo R, Oxford L, Clark A, Parikh F, Kim-Schulze S, Thompson-Snipes L, et al. Therapeutic HPV Cancer Vaccine Targeted to CD40 Elicits Effective CD8+ T-cell Immunity. Cancer Immunol Res. 2016; 4: 823-34. https:// doi.org/10.1158/2326-6066.CIR-16-0128.

18. Zhou X, Munger $\mathrm{K}$. Expression of the human papillomavirus type 16 E7 oncoprotein induces an autophagy-related process and sensitizes normal human keratinocytes to cell death in response to growth factor deprivation. Virology. 2009; 385: 192-7. https://doi. org/10.1016/j.virol.2008.12.003.

19. Bhat P, Leggatt G, Matthaei KI, Frazer IH. The kinematics of cytotoxic lymphocytes influence their ability to kill target cells. PLoS One. 2014; 9: e95248. https://doi.org/10.1371/ journal.pone.0095248.

20. Martinez-Lostao L, Anel A, Pardo J. How Do Cytotoxic Lymphocytes Kill Cancer Cells? Clin Cancer Res. 2015; 21: 5047-56. https://doi.org/10.1158/1078-0432.CCR-15-0685.

21. Satchell AC, Barnetson RS, Halliday GM. Increased Fas ligand expression by $\mathrm{T}$ cells and tumour cells in the progression of actinic keratosis to squamous cell carcinoma. Br J Dermatol. 2004; 151: 42-9. https://doi. org/10.1111/j.1365-2133.2004.05974.x.
22. Kassahn D, Nachbur U, Conus S, Micheau O, Schneider P, Simon HU, Brunner T. Distinct requirements for activationinduced cell surface expression of preformed Fas/CD95 ligand and cytolytic granule markers in $\mathrm{T}$ cells. Cell Death Differ. 2009; 16: 115-24. https://doi.org/10.1038/ cdd.2008.133.

23. Varanasi V, Avanesyan L, Schumann DM, Chervonsky AV. Cytotoxic mechanisms employed by mouse T cells to destroy pancreatic beta-cells. Diabetes. 2012; 61: 2862-70. https://doi.org/10.2337/db11-1784.

24. Mattarollo SR, Yong M, Tan L, Frazer IH, Leggatt GR. Secretion of IFN-gamma but not IL-17 by CD1d-restricted NKT cells enhances rejection of skin grafts expressing epithelial cell-derived antigen. J Immunol. 2010; 184: 56639. https://doi.org/10.4049/jimmunol.0903730.

25. Hamada H, Bassity E, Flies A, Strutt TM, Garcia-Hernandez Mde L, McKinstry KK, Zou T, Swain SL, Dutton RW. Multiple redundant effector mechanisms of CD8+ T cells protect against influenza infection. J Immunol. 2013; 190: 296-306. https://doi.org/10.4049/jimmunol.1200571.

26. Liu AN, Mohammed AZ, Rice WR, Fiedeldey DT, Liebermann JS, Whitsett JA, Braciale TJ, Enelow RI. Perforin-independent CD8(+) T-cell-mediated cytotoxicity of alveolar epithelial cells is preferentially mediated by tumor necrosis factor-alpha: relative insensitivity to Fas ligand. Am J Respir Cell Mol Biol. 1999; 20: 849-58. https://doi.org/10.1165/ajrcmb.20.5.3585.

27. White DW, Harty JT. Perforin-deficient CD8+ T cells provide immunity to Listeria monocytogenes by a mechanism that is independent of CD95 and IFN-gamma but requires TNF-alpha. J Immunol. 1998; 160: 898-905.

28. Dudek NL, Thomas HE, Mariana L, Sutherland RM, Allison J, Estella E, Angstetra E, Trapani JA, Santamaria P, Lew AM, Kay TW. Cytotoxic T-cells from T-cell receptor transgenic NOD8.3 mice destroy beta-cells via the perforin and Fas pathways. Diabetes. 2006; 55: 2412-8. https://doi. org/10.2337/db06-0109.

29. Okiyama N, Katz SI. Programmed cell death 1 (PD-1) regulates the effector function of CD8 T cells via PD-L1 expressed on target keratinocytes. J Autoimmun. 2014; 53: 1-9. https://doi.org/10.1016/j.jaut.2014.06.005.

30. Viard-Leveugle I, Gaide O, Jankovic D, Feldmeyer L, Kerl K, Pickard C, Roques S, Friedmann PS, Contassot E, French LE. TNF-alpha and IFN-gamma are potential inducers of Fas-mediated keratinocyte apoptosis through activation of inducible nitric oxide synthase in toxic epidermal necrolysis. J Invest Dermatol. 2013; 133: 48998. https://doi.org/10.1038/jid.2012.330.

31. Bergmann-Leitner ES, Abrams SI. Influence of interferon gamma on modulation of Fas expression by human colon carcinoma cells and their subsequent sensitivity to antigenspecific CD8+ cytotoxic T lymphocyte attack. Cancer Immunol Immunother. 2000; 49: 193-207.

32. Qin H, Trudeau JD, Reid GS, Lee IF, Dutz JP, Santamaria $\mathrm{P}$, Verchere CB, Tan R. Progression of spontaneous 
autoimmune diabetes is associated with a switch in the killing mechanism used by autoreactive CTL. Int Immunol. 2004; 16: 1657-62. https://doi.org/10.1093/ intimm/dxh167.

33. Corazza N, Muller S, Brunner T, Kagi D, Mueller C. Differential contribution of Fas- and perforin-mediated mechanisms to the cell-mediated cytotoxic activity of naive and in vivo-primed intestinal intraepithelial lymphocytes. J Immunol. 2000; 164: 398-403.

34. Simon MM, Waring P, Lobigs M, Nil A, Tran T, Hla RT, Chin S, Mullbacher A. Cytotoxic T cells specifically induce Fas on target cells, thereby facilitating exocytosisindependent induction of apoptosis. J Immunol. 2000; 165: 3663-72.

35. Kafrouni MI, Brown GR, Thiele DL. Virally infected hepatocytes are resistant to perforin-dependent CTL effector mechanisms. J Immunol. 2001; 167: 1566-74.

36. Motz GT, Santoro SP, Wang LP, Garrabrant T, Lastra RR, Hagemann IS, Lal P, Feldman MD, Benencia F, Coukos G. Tumor endothelium FasL establishes a selective immune barrier promoting tolerance in tumors. Nat Med. 2014; 20: 607-15. https://doi.org/10.1038/nm.3541.

37. Thompson DA, Zacny V, Belinsky GS, Classon M, Jones DL, Schlegel R, Munger K. The HPV E7 oncoprotein inhibits tumor necrosis factor alpha-mediated apoptosis in normal human fibroblasts. Oncogene. 2001; 20: 3629-40. https://doi.org/10.1038/sj.onc.1204483.

38. Galenkamp KM, Carriba P, Urresti J, Planells-Ferrer L, Coccia E, Lopez-Soriano J, Barneda-Zahonero B, Moubarak RS, Segura MF, Comella JX. TNFalpha sensitizes neuroblastoma cells to FasL-, cisplatin- and etoposide-induced cell death by NF-kappaB-mediated expression of Fas. Mol Cancer. 2015; 14: 62. https://doi. org/10.1186/s12943-015-0329-x.

39. Mezache L, Paniccia B, Nyinawabera A, Nuovo GJ. Enhanced expression of PD L1 in cervical intraepithelial neoplasia and cervical cancers. Mod Pathol. 2015; 28: 1594-602. https://doi.org/10.1038/modpathol.2015.108.

40. Severson JJ, Serracino HS, Mateescu V, Raeburn CD, McIntyre RC Jr, Sams SB, Haugen BR, French JD. PD-1+Tim-3+ CD8+ T Lymphocytes Display Varied Degrees of Functional Exhaustion in Patients with Regionally Metastatic Differentiated Thyroid Cancer. Cancer Immunol Res. 2015; 3: 620-30. https://doi. org/10.1158/2326-6066.CIR-14-0201.

41. Romero D. Immunotherapy: PD-1 says goodbye, TIM-3 says hello. Nat Rev Clin Oncol. 2016; 13: 202-3. https:// doi.org/10.1038/nrclinonc.2016.40.

42. Shadrin N, Shapira MG, Khalfin B, Uppalapati L, Parola $\mathrm{AH}$, Nathan I. Serine protease inhibitors interact with IFNgamma through up-regulation of FasR; a novel therapeutic strategy against cancer. Exp Cell Res. 2015; 330: 233-9. https://doi.org/10.1016/j.yexcr.2014.11.005.

43. Rice AE, Latchman YE, Balint JP, Lee JH, Gabitzsch ES, Jones FR. An HPV-E6/E7 immunotherapy plus PD-1 checkpoint inhibition results in tumor regression and reduction in PD-L1 expression. Cancer Gene Ther. 2015; 22: 454-62. https://doi.org/10.1038/cgt.2015.40.

44. Beyranvand Nejad E, van der Sluis TC, van Duikeren S, Yagita H, Janssen GM, van Veelen PA, Melief CJ, van der Burg SH, Arens R. Tumor Eradication by Cisplatin Is Sustained by CD80/86-Mediated Costimulation of CD8+ T Cells. Cancer Res. 2016; 76: 6017-29. https://doi. org/10.1158/0008-5472.CAN-16-0881. 